\title{
Belimumab in Systemic Lupus Erythematosus - What Can Be Learned from Longterm Observational Studies?
}

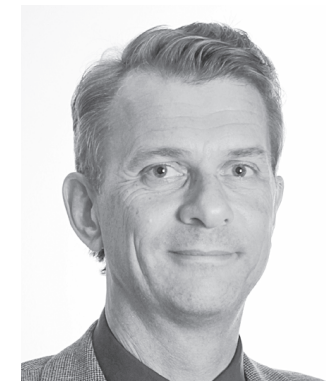

Most patients with systemic lupus erythematosus (SLE) do not have optimal disease control ${ }^{1}$. Despite the available SLE treatments of today, patients still have flares, and some low-grade disease activity can be seen in many patients when followed over time. As a consequence of both chronic inflammation and use of corticosteroids, irreversible organ damage such as osteoporosis and cardiovascular disease may occur. In fact, disease activity over time has a great influence on organ damage and other outcomes ${ }^{2,3}$, and it is obvious that sustained control of disease activity is desirable in SLE. One such possibility of achieving longterm disease control and prevention of flare is published in the current issue of The Journal ${ }^{4}$, where data are presented from an observational study in patients with SLE treated with belimumab for 7 years.

Tumor necrosis factor blockers and other biological therapies have been used in rheumatoid arthritis and spondyloarthropathies for many years now, and this has dramatically changed the rheumatologic landscape. Meanwhile, phase III placebo-controlled randomized clinical trials (RCT) of different biologic therapies in the treatment of SLE have been unsuccessful - until the BLISS studies. The BLISS- $52^{5}$ and BLISS- $76^{6}$ studies are RCT in which treatment with belimumab showed significant effects on disease activity in SLE, and these studies formed the basis for the US Food and Drug Administration and European Medicines Agency approval. In contrast, 2 RCT with rituximab, $1 \mathrm{renal}^{7}$ and 1 non-renal ${ }^{8}$, failed to show significant effects. This was somewhat a surprise because this anti-B cell therapy has been used off-label to treat refractory cases with success as described in case series ${ }^{9}$. Also, phase III trials with abatacept (CTLA4-Ig), inhibiting $\mathrm{T}$ cell costimulation, failed to reach primary outcomes ${ }^{10}$. Thus, the way to approval for a first biologic in SLE has indeed not been straightforward, probably because of the difficulties in designing optimal RCT in this complex disease, which could be kept in mind when critically evaluating the belimumab studies.
Immune complexes and pathogenic autoantibodies produced by B cells and plasma cells are still considered central in SLE pathogenesis although numerous proteins and cell types in different pathways are involved. B lymphocyte stimulator (BLyS) is a suitable target because it is a survival factor for B cells. Belimumab binds to soluble BLyS, which retards further development into plasma cells and immunoglobulin production ${ }^{11}$. This mode of action may give some clues to which patients with SLE are more responsive to belimumab, and the studies accordingly demonstrate that patients with anti-dsDNA antibodies and low complement are more responsive to this therapy ${ }^{12}$. The identification of which SLE subgroup is most suitable for belimumab treatment is at present based on the results from the RCT. Patients with mucocutaneous and articular manifestations were most frequently represented in the BLISS studies, but patients with severe nephritis and central nervous system involvement, where anti-dsDNA antibodies and low complement are more markedly altered, are less studied. Future studies with other clinical phenotypes, in combination with experiences from clinical practice, will most likely modify our view of who will benefit most from this treatment.

But for how long should we treat? According to the BLISS studies it takes 6 to 12 months before a significant difference can be seen in response to treatment as assessed by the SLE Responder Index (SRI). The development of the SRI was very important for the belimumab trials ${ }^{13}$. The SRI identifies both improvement and lack of worsening, but it is a dichotomous variable, which means that any patients who happen to respond partially earlier may not be detected until they are responders according to the criteria of the SRI. More important, the SRI was developed as a robust and reliable tool for RCT in SLE, but the index will probably not be frequently used outside the settings of clinical trials. Still, the information we have to date - and have to rely on - is the studies using SRI as an endpoint, telling us that it may take 6-12 months

\section{See Disease control and safety of belimumab, page 300}


before you are sure that a patient is a nonresponder to belimumab treatment.

The BLISS studies give us, however, less information on how long we should continue to treat patients who are responsive to belimumab treatment and have acceptable side effects. On the other hand, there are few studies examining withdrawal of any therapy in SLE, and the best studied seems to be antimalarial treatment. There is evidence that this treatment should be continued because withdrawal is associated with increased risk for flares, and longterm treatment has protective effects on the cardiovascular side ${ }^{14}$.

The present investigation by Ginzler, et al is important because we now have one of the few longterm studies on SLE therapy. It is an open-label extension of the phase II study $^{12}$ that preceded the BLISS studies, and the results are therefore derived from a self-selected population of belimumab responders. Out of 449 patients started in the phase II study, 321 were eligible for the open extension study, and of those, 221 were autoantibody positive. After 7 years, 177 patients remained in the study, of whom 135 belonged to the group with autoantibodies at start. Thus, it is obvious that the design of this observational study may cause an enrichment of patients that responded well to and tolerated belimumab, which will influence the results. Nevertheless, these 7-year extension data indicate a possibility of increased efficacy over time in terms of SRI responders, a decrease in severe flares, a marked decrease in corticosteroid use, and improvement of biomarkers. Efficacy considerations are, however, troublesome because of the lack of a control group, which makes it difficult to evaluate and interpret the results and raises the question of the disease course seen in responders to longterm treatment with conventional SLE treatment.

Observational studies may be important for assessing the longterm safety profile and rare side effects. An acceptable safety profile has been reported from the same study population after 4 years of followup ${ }^{15}$, and the Ginzler study now with 7 years of followup did not reveal any evidently different patterns. Also, more analysis of nonresponders and reasons for treatment withdrawal could provide us with additional valuable information.

Additional longterm studies that include treatments and outcome will provide us with more data, aiding us in how to use biological and other drugs in the treatment of SLE. To reach this goal, inclusion of control or contrast groups, partial responders to therapy, and more phenotypically defined treatment groups would be desirable.

\footnotetext{
Department of Clinical Sciences,

Rheumatology,

University Hospital Lund,

Lund 22185, Sweden.
}

ANDERS A. BENGTSSON, MD, PhD

Address correspondence to Dr. Bengtsson.

E-mail: Anders.Bengtsson@med.lu.se

\section{REFERENCES}

1. Nikpour M, Urowitz MB, Ibanez D, Gladman DD. Frequency and determinants of flare and persistently active disease in systemic lupus erythematosus. Arthritis Rheum 2009;61:1152-8.

2. Becker-Merok A, Nossent HC. Damage accumulation in systemic lupus erythematosus and its relation to disease activity and mortality. J Rheumatol 2006;33:1570-7.

3. McCarthy EM, Lee RZ, Ni Gabhann J, Smith S, Cunnane G, Doran $\mathrm{MF}$, et al. Elevated B lymphocyte stimulator levels are associated with increased damage in an Irish systemic lupus erythematosus cohort. Rheumatology 2013;52:1279-84.

4. Ginzler EM, Wallace DJ, Merrill JT, Furie RA, Stohl W, Chatham WW, et al. Disease control and safety of belimumab plus standard therapy over 7 years in patients with systemic lupus erythematosus. J Rheumatol 2014;41:300-9.

5. Navarra SV, Guzman RM, Gallacher AE, Hall S, Levy RA, Jimenez RE, et al. Efficacy and safety of belimumab in patients with active systemic lupus erythematosus: a randomised, placebo-controlled, phase 3 trial. Lancet 2011;377:721-31.

6. Furie R, Petri M, Zamani O, Cervera R, Wallace DJ, Tegzova D, et al. A phase III, randomized, placebo-controlled study of belimumab, a monoclonal antibody that inhibits B lymphocyte stimulator, in patients with systemic lupus erythematosus. Arthritis Rheum 2011;63:3918-30.

7. Rovin BH, Furie R, Latinis K, Looney RJ, Fervenza FC, Sanchez-Guerrero J, et al. Efficacy and safety of rituximab in patients with active proliferative lupus nephritis: the Lupus Nephritis Assessment with Rituximab study. Arthritis Rheum 2012;64:1215-26.

8. Merrill JT, Neuwelt CM, Wallace DJ, Shanahan JC, Latinis KM, Oates JC, et al. Efficacy and safety of rituximab in moderately-to-severely active systemic lupus erythematosus: the randomized, double-blind, phase II/III systemic lupus erythematosus evaluation of rituximab trial. Arthritis Rheum 2010;62:222-33

9. Ng KP, Cambridge G, Leandro MJ, Edwards JC, Ehrenstein M, Isenberg DA. B cell depletion therapy in systemic lupus erythematosus: long-term follow-up and predictors of response. Ann Rheum Dis 2007;66:1259-62.

10. Merrill JT, Burgos-Vargas R, Westhovens R, Chalmers A, D'Cruz $\mathrm{D}$, Wallace DJ, et al. The efficacy and safety of abatacept in patients with non-life-threatening manifestations of systemic lupus erythematosus: results of a twelve-month, multicenter, exploratory, phase IIb, randomized, double-blind, placebo-controlled trial. Arthritis Rheum 2010;62:3077-87.

11. Davidson A. The rationale for BAFF inhibition in systemic lupus erythematosus. Curr Rheumatol Rep 2012;14:295-302.

12. Wallace DJ, Stohl W, Furie RA, Lisse JR, McKay JD, Merrill JT, et al. A phase II, randomized, double-blind, placebo-controlled, dose-ranging study of belimumab in patients with active systemic lupus erythematosus. Arthritis Rheum 2009;61:1168-78.

13. Furie RA, Petri MA, Wallace DJ, Ginzler EM, Merrill JT, Stohl W, et al. Novel evidence-based systemic lupus erythematosus responder index. Arthritis Rheum 2009;61:1143-51.

14. Ruiz-Irastorza G, Ramos-Casals M, Brito-Zeron P, Khamashta MA. Clinical efficacy and side effects of antimalarials in systemic lupus erythematosus: a systematic review. Ann Rheum Dis 2010;69:20-8.

15. Merrill JT, Ginzler EM, Wallace DJ, McKay JD, Lisse JR, Aranow $\mathrm{C}$, et al. Long-term safety profile of belimumab plus standard therapy in patients with systemic lupus erythematosus. Arthritis Rheum 2012;64:3364-73.

J Rheumatol 2014;41:192-3; doi:3899/jrheum.131378 Personal non-commercial use only. The Journal of Rheumatology Copyright (C) 2014. All rights reserved. 